\title{
Distinctive expression of TMEM132A and its regulation after the nerve injury in the DRG
}

\author{
Ghoshun Shimosato $^{1 \#}$, Kentaro Oh-hashi ${ }^{2,3 * *}$, Yosuke Yamaguchi ${ }^{1}$ and Fumimasa Amaya ${ }^{1}$ \\ ${ }^{1}$ Department of Anesthesiology, Kyoto Prefectural University of Medicine, Japan \\ ${ }^{2}$ Department of Chemistry and Biomolecular Science, Faculty of Engineering, Gifu University, Japan \\ ${ }^{3}$ United Graduate School of Drug Discovery and Medical Information Sciences, Gifu University, Japan \\ \#These authors contributed equally to this work
}

\begin{abstract}
Transmembrane protein (TMEM)132A is a 78-kDa glucose-regulated protein (GRP78)-binding protein expressed in the central nervous system of rat and has been shown to have a certain pro-survival function in a cultured neuronal cell line. In general, primary afferent neurons in the dorsal root ganglion (DRG) have unique characteristics in terms of stress response after the nerve injury; medium to large myelinated A-fiber neurons survive after the sciatic nerve axotomy while small unmyelinated $\mathrm{C}$-fiber neurons progressively undergo cell death. We investigated the expression of TMEM132A protein and mRNA by immunohistochemistry and in situ hybridization in rat DRG. The number of TMEM132A-positive neurons was compared between control and axotomized rats. TMEM132A was expressed in the primary afferent neurons in the DRG in the control rats. Most of TMEM132A positive neurons lacked immunoreactivity of peripherin, a marker for C-fiber neurons, indicating that TMEM132A expression was limited to the medium to large myelinated A-fiber neurons that are known to survive even after the axotomy. After sciatic nerve axotomy, TMEM132A mRNA expression decreased rapidly. These findings demonstrated that TMEM132A was present in the primary afferent neurons and suggest its important role after the nerve injury.
\end{abstract}

\section{Introduction}

$78-\mathrm{kDa}$ glucose-regulated protein (GRP78) having roles in controlling protein folding and regulating unfolded protein responses within endoplasmic reticulum (ER) is one of ER stress markers, and it is implicated that fluctuation of GRP78 expression is associated with many neurodegenerative diseases [1]. We previously identified a novel GRP78-binding protein using PCR-selected cDNA subtraction to isolate a novel gene enriched in the embryonic and postnatal stages of rat brain development [2]. TMEM132A mRNA was found to be predominantly expressed in brain [2,3]. It encodes putative transmembrane domains and is renamed as transmembrane protein 132A, TMEM132A. TMEM132A mRNA is present in the E12 rat brain, and gradually increases and peaks during postnatal $0-2$ weeks and decreases with aging.

The biological functions of TMEM132A have not been deducible from its amino acid sequence because it does not encode any known structural domains. TMEM132A-overexpression in Neuro2a cells partially suppressed serum starvation-induced cell death [2] suggesting that TMEM132A might have functional roles for neuronal survival. Our recent study on the subcellular localization of TMEM132A using cell-surface biotinylation and immunocytochemistry revealed that TMEM132A is not only localized in the ER-Golgi apparatus, but also present at the cell surface, and its $\mathrm{N}$-terminus is exposed to the extracellular space. These results suggest that TMEM132A might play a role in the perception of extracellular signals and/or cell-cell communication [3].

Adult dorsal root ganglion (DRG) neurons have unique stress response against the nerve injury. Neurons with unmyelinated C-fiber undergo cell death after the axotomy, while most of myelinated A-fiber neurons survive for longer periods [4]. The precise mechanism by which A-fiber neurons can survive long after the axotomy remains unclear.

In this study, we first characterized the cell expressing TMEM132A in rat DRG by in situ hybridization and immunostaining. TMEM132A expression was mainly localized in myelinated neurons but decreased by the axotomy, implicating biological functions for selective neuronal survival by the nerve injury.

\section{Materials and methods}

\section{Animal treatment}

Experiments were approved by the Kyoto Prefectural University of Medicine animal care committee and were in accordance with the guidelines of the National Institutes of Health. Male Sprague-Dawley rats (Shimizu Laboratory Supplies CO., Ltd., Japan) weighing 200-250g were used for this study. All of surgical procedure was done under general anesthesia with isoflurane (1-3\% v/v). Ten-mm-long segment of the left sciatic nerve was exposed at the mid-thigh level and strongly ligated and transected. Fourteen days after the axotomy, animals were

Correspondence to: Kentaro Oh-hashi, Department of Chemistry and Biomolecular Science, Faculty of Engineering, Gifu University, 1-1 Yanagido, Gifu 501-1193, Japan, Tel; +81-58-293-2659; Fax; +81-58-293-2794; E-mail: oohashi@gifu-u.ac.jp

Key words: transmembrane protein $132 \mathrm{~A}$, peripherin, $78 \mathrm{kDa}$ glucose-regulated protein

Received: October 15, 2016; Accepted: October 23, 2016; Published: October 26,2016 
perfused with $0.9 \% \mathrm{NaCl}$ followed by $4 \%$ paraformaldehyde (PFA) in $0.1 \mathrm{M}$ phosphate buffer $(\mathrm{PB})$ under terminal anesthesia with isoflurane. L4 and L5 DRG tissues were taken, cryoprotected with 20\% sucrose for $24 \mathrm{~h}$, frozen and kept at $-80^{\circ} \mathrm{C}$ until use. Transverse sections through the DRG were cut on a cryostat in $10 \mu \mathrm{m}$ thickness and mounted onto Silane-Prep microscope slides (Sigma, MO, USA).

\section{In situ hybridyzation}

Visualization of TMEM132A mRNA was performed using digoxigenin (DIG) labeled RNA probe transcribed from rat TMEM cDNA subcloned into pGEM-T Easy vector as described previously [5]. Sections were washed in $0.1 \mathrm{M}$ phosphate buffered saline (PBS) for $15 \mathrm{~min}$ at $4^{\circ} \mathrm{C}$. Acetylated in $0.25 \%$ acetic anhydride in $0.1 \mathrm{M}$ triethanolamine for $15 \mathrm{~min}$ at room temperature, sections were hybridized with riboprobe diluted in hybridization buffer (Sigma, MO, USA) at $60^{\circ} \mathrm{C}$ for $12 \mathrm{~h}$ in a humidified chamber. Sections were washed in $5 \times$ SSC for $10 \mathrm{~min}, 0.2 \times$ SSC for $15 \mathrm{~min}$, and $0.1 \times$ SSC for $30 \mathrm{~min}$ at $60^{\circ} \mathrm{C}$ and incubated with anti-DIG-AP antibody (1:1000, Roche, Switzerland) in DIG buffer 1 (100 mM Tris- $\mathrm{HCl} \mathrm{pH} \mathrm{7.5,150} \mathrm{mM} \mathrm{NaCl)}$ for $12 \mathrm{~h}$ at $4^{\circ} \mathrm{C}$. Signals were visualized by incubating with $4.5 \mu \mathrm{l} / \mathrm{ml}$ of 5-bromo-4-chloro-3-indolyl-phosphate and $3.5 \mu \mathrm{l} / \mathrm{ml}$ of 4 -Nitroblue tetrazolium chloride in DIG buffer $3(100 \mathrm{mM}$ Tris- $\mathrm{HCl} \mathrm{pH}$ 7.5, 100 $\mathrm{mM} \mathrm{NaCl}, 50 \mathrm{mM} \mathrm{MgCl}$ ).

\section{Immunohistochemistry}

Double labeling immunohistochemistry was performed with TMEM132A and peripherin, a marker for neurons with unmyelinated axon as described previously [6]. Sections were washed and incubated with a rabbit anti-TMEM132A polyclonal antibody [7] and mouse anti-peripherin (Millipore, 1:200) at $4^{\circ} \mathrm{C}$ for 3days. Washed again, sections were incubated with anti-rabbit rhodamine and anti-mouse FITC overnight at $4^{\circ} \mathrm{C}$.

\section{Results and discussion}

TMEM132A mRNA was detected as intense digoxigenin staining in cell bodies of DRG neurons (Figure1). In control DRG, 50 to $60 \%$ of neurons were positive for TMEM132A mRNA. Most of the TMEM132A mRNA positive neurons had medium to large sized cell bodies. Hybridization without the probe did not show any staining, confirming the probe specificity. We observed similar distribution pattern of TMEM132A protein by fluorescent immunohistochemistry (Figure 2). Double labeling study revealed approximately $30 \%$ of TMEM132A expressing neurons was positive for peripherin, specific

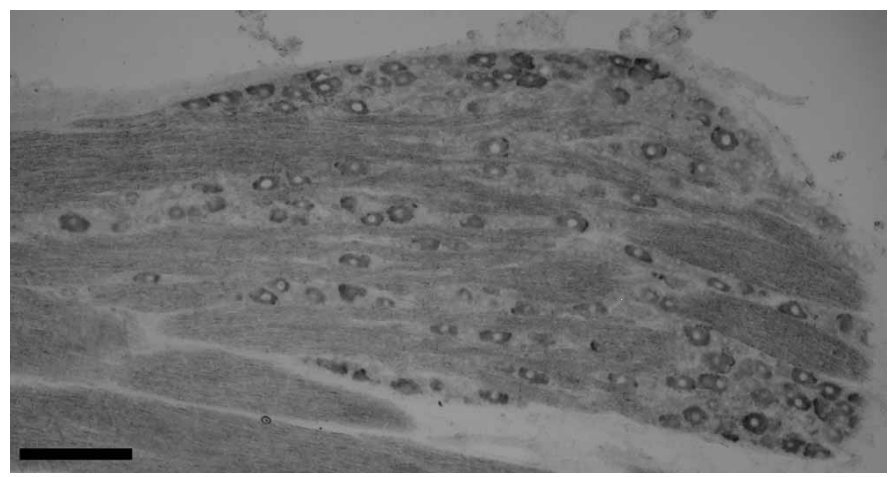

Figure 1. In situ hybridization for TMEM132A mRNA in naive rat DRG. TMEM132A mRNA was detected primary afferent neurons in the DRG. Most of TMEM132A-positive neurons were medium to large sized neurons. Scale bar $=100 \mu \mathrm{m}$.
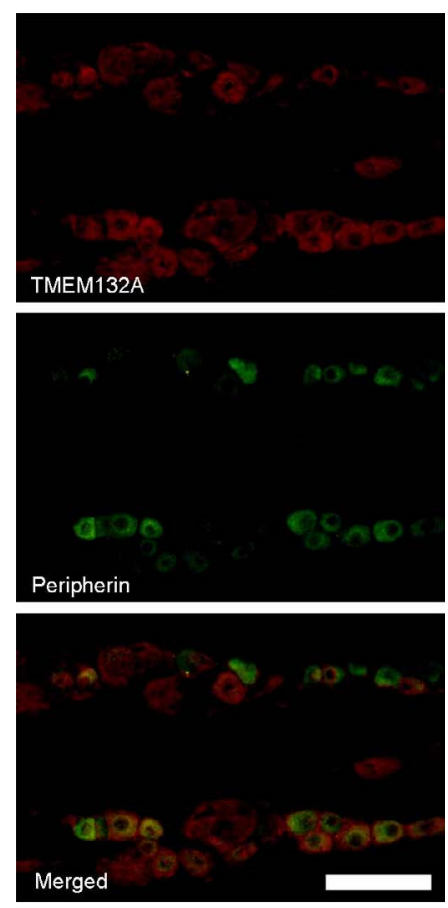

Figure 2. Double labeling immunohistochemistry for TMEM132A and peripherin, a marker for $\mathrm{C}$-fiber neuron, in naive rat DRG. Red signals in upper column indicate TMEM132A immunoreactivity and green signals in middle column indicate peripherin immunoreactivity. Double labeled neurons were indicated as yellow signals in merged (lower) column. Most of TMEM132A immunoreactivity did not co-localize with peripherin signal. Scale bar $=100 \mu \mathrm{m}$.

marker for unmyelinated neurons [8], while the remaining 70\% lacked peripherin signal.

Following the nerve injury, intensity of TMEM132A signals in each neurons as well as the number of TMEM132A mRNA-expressing neurons in the DRG decreased rapidly (Figure 3, middle column). The number of TMEM132A mRNA positive neurons decreased significantly two days after the axotomy and continued to decrease at least 14 days thereafter (Figure 3, lower column).

In the present investigation, we demonstrated substantial expression of TMEM132A in adult primary afferent neurons for the first time. In the DRG, TMEM132A is predominantly expressed in neuronal cells. This is consistent with our previous study that showed neuronal cells-specific expression of TMEM132A mRNA in several rat brain regions [2]. TMEM132A expression in DRG showed unique distribution profile, with medium to large myelinated neurons dominantly expressing it. Myelinated neurons in the DRG are known to survive for long after the axotomy, while unmyelinated neurons undergo progressive cell death [4]. Together with our previous in vitro study showing a pro-survival function of TMEM132A [2] and fluctuations of several genes including ER stress-related genes (ATF6 and GADD153) by transient knock-down of TMEM132A [9], the current observation implicates an important role of TMEM132A for the selective survival of the myelinated neurons after the nerve injury.

We previously reported that TMEM132A mRNA gradually increases at the embryonic stages, peaks during postnatal 0-2 weeks and decreases with aging in rat brain [2]. In contrast to the expression of TMEM132A during development, to our knowledge it has not been reported whether the expression of TMEM132A would change under pathophysiological conditions. In the present study, we first demonstrate 

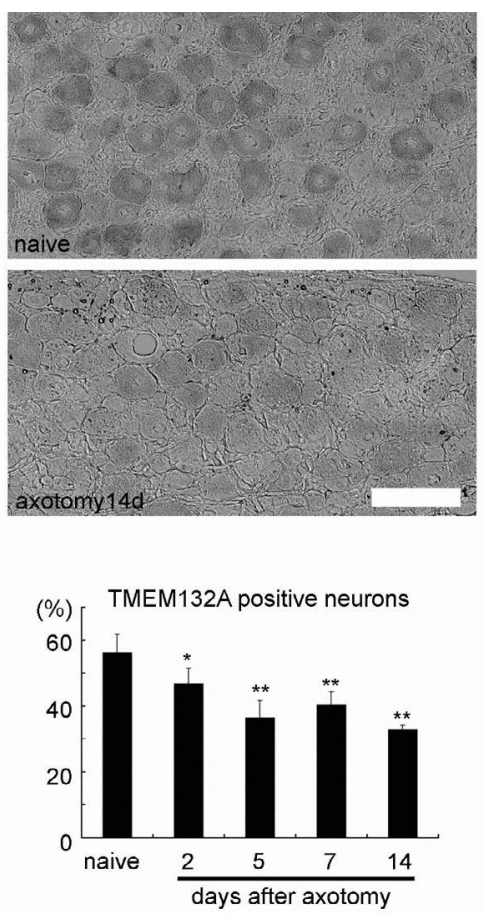

Figure 3. Regulation of TMEM132A mRNA after the sciatic nerve axotomy.

TMEM132A mRNA expression decreased after the axotomy (lower column) compared to control (upper column). Scale bar $=100 \mu \mathrm{m}$. The number of TMEM132A mRNA positive neurons decreased 2days after axotomy and continued decreasing up to 14days. $\mathrm{N}=5$ ${ }^{*} \mathrm{p}<0.05, * * \mathrm{p}<0.01$ vs. control.

that the expression of TMEM132A decreased rapidly following the sciatic nerve axotomy. TMEM132A was originally identified as a novel GRP78-binding protein and predominantly localized in ER. GRP78 is one of the ER resident chaperones and regulates protein folding and intracellular trafficking of various proteins [10]. GRP78 prevents ER stress-induced cell death [11] by modulating ER stress transducers such as PERK, IRE, ATF6 and caspase-12 [12-14]. Interestingly, our previous study showed that GRP78 regulates the glycosylation of TMEM132A by transiently overexpressing GRP78 together with TMEM132A [3]. However, more characterization of TMEM132A and GRP78 in the DRG as well as their interaction in vivo are required in the future study.

We also reported that TMEM132A participates in cAMP-induced GFAP mRNA expression through STAT3 signaling pathways in C6 glioblastoma cells [7], although the precise mechanisms remain to be determined. The N-terminus of TMEM132A protein has been shown to be exposed to the extracellular space by transient overexpression of TMEME132A in cell-lines [3]. Considering these findings, TMEM132A might play a role in the perception of extracellular signals and/or cell-cell communication in the nervous systems. In preliminary experiment, we detected TMEM132A mRNA is weakly expressed in primary cultured glial cells, microglias and astrocytes, from rat cerebral cortex. In the DRG, TMEM132A was also weakly expressed in GFAPpositive satellite cells (data not shown). It has also been reported that acute spinal cord injury rapidly elevates the phosphoryation of STAT3 in the DRG [15]. Therefore, a more precise analysis of TMEM132A in relation to GRP78 and STAT3 signaling pathways should reveal a novel therapeutic approach to central and peripheral nerve injuries and neurodegenerative diseases.

In conclusion, we investigated expression of TMEM132A, one of the GRP78-binding proteins in the DRG. TMEM132A was expressed medium to large primary afferent neurons and decreased after the nerve injury. TMEM132A might have some important role in stress response after the nerve injury.

\section{Acknowledgements}

We thank Dr. Nagase and Dr. Koga for providing an antibody against TMEM132A.

\section{References}

1. Gorbatyuk MS, Gorbatyuk OS (2013) The Molecular Chaperone GRP78/BiP as a Therapeutic Target for Neurodegenerative Disorders: A Mini Review. J Genet Syndr Gene Ther 4. [Crossref]

2. Oh-hashi K, Naruse Y, Amaya F, Shimosato G, Tanaka M (2003) Cloning and characterization of a novel GRP78-binding protein in the rat brain. J Biol Chem 278: 10531-10537. [Crossref]

3. Oh-hashi K, Koga H, Nagase T, Hirata Y, Kiuchi K (2012) Characterization of the expression and cell-surface localization of transmembrane protein 132A. Mol Cell Biochem 370: 23-33. [Crossref]

4. Tandrup T, Woolf CJ, Coggeshall RE (2000) Delayed loss of small dorsal root ganglion cells after transection of the rat sciatic nerve. J Comp Neurol 422: 172-180. [Crossref]

5. Amaya F, Shimosato G, Kawasaki Y, Hashimoto S, Tanaka Y, et al. (2006) Induction of CB1 cannabinoid receptor by inflammation in primary afferent neurons facilitates antihyperalgesic effect of peripheral CB1 agonist. Pain 124: 175-183. [Crossref]

6. Amaya F, Shimosato G, Nagano M, Ueda M, Hashimoto S, et al. (2004) NGF and GDNF differentially regulate TRPV1 expression that contributes to development of inflammatory thermal hyperalgesia. Eur J Neurosci 20: 2303-2310. [Crossref]

7. Oh-hashi K, Hirata Y, Koga H, Kiuchi K (2006) GRP78-binding protein regulates cAMP-induced glial fibrillary acidic protein expression in rat C6 glioblastoma cells. FEBS Lett 580: 3943-3947. [Crossref]

8. Larivière RC, Nguyen MD, Ribeiro-da-Silva A, Julien JP (2002) Reduced number of unmyelinated sensory axons in peripherin null mice. J Neurochem 81: 525-532. [Crossref]

9. Oh-hashi K, Imai K, Koga H, Hirata Y, Kiuchi K (2010) Knockdown of transmembrane protein $132 \mathrm{~A}$ by RNA interference facilitates serum starvation-induced cell death in Neuro2a cells. Mol Cell Biochem 342: 117-123. [Crossref]

10. Kleizen B, Braakman I (2004) Protein folding and quality control in the endoplasmic reticulum. Curr Opin Cell Biol 16: 343-349. [Crossref]

11. Yu Z, Luo H, Fu W, Mattson MP (1999) The endoplasmic reticulum stress-responsive protein GRP78 protects neurons against excitotoxicity and apoptosis: suppression of oxidative stress and stabilization of calcium homeostasis. Exp Neurol 155: 302-314. [Crossref]

12. Bertolotti A, Zhang Y, Hendershot LM, Harding HP, Ron D (2000) Dynamic interaction of $\mathrm{BiP}$ and ER stress transducers in the unfolded-protein response. Nat Cell Biol 2: 326-332. [Crossref]

13. Shen J, Chen X, Hendershot L, Prywes R (2002) ER stress regulation of ATF6 localization by dissociation of BiP/GRP78 binding and unmasking of Golgi localization signals. Dev Cell 3: 99-111. [Crossref]

14. Rao RV, Peel A, Logvinova A, del Rio G, Hermel E, et al. (2002) Coupling endoplasmic reticulum stress to the cell death program: role of the ER chaperone GRP78. FEBS Lett 514: 122-128. [Crossref]

15. Tsai SY, Yang LY, Wu CH, Chang SF, Hsu CY, et al. (2007) Injury-induced Janus kinase/protein kinase C-dependent phosphorylation of growth-associated protein 43 and signal transducer and activator of transcription 3 for neurite growth in dorsal root ganglion. J Neurosci Res 85: 321-331. [Crossref]

Copyright: (C2016 Shimosato G. This is an open-access article distributed under the terms of the Creative Commons Attribution License, which permits unrestricted use, distribution, and reproduction in any medium, provided the original author and source are credited. 